\title{
An overview of hydrometeorological datasets from a small agricultural catchment (Nučice) in the Czech Republic
}

\author{
Tailin $\mathrm{Li}^{1}$, Jakub Jeřábek ${ }^{1}$, Nina Noreika ${ }^{1}$, Tomáš Dostál ${ }^{1}$, and David Zumr ${ }^{1}$ \\ ${ }^{1}$ Czech Technical University in Prague
}

October 1, 2020

\begin{abstract}
In this study, we introduce datasets that include both hydrological and meteorological records at the Nučice experimental catchment $(0.53 \mathrm{~km} 2)$ which is representative for an intensively farmed landscape in the Czech Republic. The Nučice experimental catchment was established in 2011 for the observation of rainfall-runoff processes, soil erosion processes, and water balance of a cultivated landscape. The average altitude is $401 \mathrm{~m}$ a.s.l., the mean land slope is $3.9 \%$, and the climate is humid continental (mean annual temperature $7.9{ }^{\circ} \mathrm{C}$, annual precipitation $630 \mathrm{~mm}$ ). The catchment is drained by an artificially straightened stream and consists of three fields covering over $95 \%$ of the area which are managed by two different farmers. The typical crops are winter wheat, rapeseed, and alfalfa. The installed equipment includes a standard meteorological station, several rain gauges distributed across the basin, and an H-flume that monitors stream discharge, water turbidity, and basic water quality indicators. Additionally, the groundwater level and soil water content at various depths near the stream are recorded. Recently, large-scale soil moisture monitoring efforts have been introduced with the installation of two cosmic-ray soil moisture sensors. The datasets consist of measured precipitation, air temperature, stream discharge, and soil moisture and are available online for public use. The cross seasonal, open access runoff generation datasets at this small-scale agricultural catchment will benefit not only hydrologists but also local farmers.
\end{abstract}

Tailin Li*, Jakub Jeřábek, Nina Noreika, Tomáš Dostál, David Zumr ${ }^{1}$

${ }^{1}$ Faculty of Civil Engineering, Czech Technical University in Prague, Prague, Czech Republic

* Corresponding Author: tailin.li@fsv.cvut.cz; Mailing Address: Thákurova 7, 16629 Praha 6, Prague, Czech Republic

Abstract: In this study, we introduce datasets that include both hydrological and meteorological records at the Nučice experimental catchment $\left(0.53 \mathrm{~km}^{2}\right)$ which is representative for an intensively farmed landscape in the Czech Republic. The Nučice experimental catchment was established in 2011 for the observation of rainfall-runoff processes, soil erosion processes, and water balance of a cultivated landscape. The average altitude is $401 \mathrm{~m}$ a.s.l., the mean land slope is $3.9 \%$, and the climate is humid continental (mean annual temperature $7.9{ }^{\circ} \mathrm{C}$, annual precipitation $630 \mathrm{~mm}$ ). The catchment is drained by an artificially straightened stream and consists of three fields covering over $95 \%$ of the area which are managed by two different farmers. The typical crops are winter wheat, rapeseed, and alfalfa. The installed equipment includes a standard meteorological station, several rain gauges distributed across the basin, and an H-flume that monitors stream discharge, water turbidity, and basic water quality indicators. Additionally, the groundwater level and soil water content at various depths near the stream are recorded. Recently, large-scale soil moisture monitoring efforts have been introduced with the installation of two cosmic-ray soil moisture sensors. The datasets consist of measured precipitation, air temperature, stream discharge, and soil moisture and are available online for public use. The cross seasonal, open access runoff generation datasets at this small-scale agricultural catchment will benefit not only hydrologists but also local farmers. 
Keywords: agricultural catchment, hydrology, soil moisture, hydrological modelling

\section{Site description}

The Nučice experimental catchment was established in 2011 with the main aim to study water balance of the cultivated fields and rainfall-runoff and soil erosion processes. The catchment is $0.531 \mathrm{~km}^{2}$ and located 30 $\mathrm{km}$ east of Prague in an intensively agricultural landscape in the Central Bohemian Region, Czech Republic (catchment outlet location $49^{\circ} 57^{\prime} 49.230^{\prime \prime} \mathrm{N}, 14^{\circ} 52^{\prime} 13.242^{\prime \prime} \mathrm{E}$ ). The morphological management and climatic conditions are representative for farmlands of the Czech Republic. The area belongs to the moderately hilly Bohemian Massif, the catchment has the average altitude of $401 \mathrm{~m}$ a.s.l. and slopes ranging from $1 \%$ to $12 \%$. The climate is humid continental with average annual precipitation of $630 \mathrm{~mm}$ from 1975 to 2015, potential evapotranspiration between 500 and $550 \mathrm{~mm}$, and mean annual air temperature of $7.9{ }^{\circ} \mathrm{C}$. The catchment is drained by a $950 \mathrm{~m}$ long, narrow stream which has been piped in the uppermost part. The channel has a trapezoidal cross-section that is $0.6 \mathrm{~m}$ wide at the stream bed with an average depth of $1.5 \mathrm{~m}$ (Figure 1).

The area of the catchment is almost exclusively covered by arable land. Less than $5 \%$ of the area consists of the stream, paved roads and shrublands. The fields are tilled to the edge of the stream banks; grass strips are missing, therefore the surface runoff and eroded soil may enter the stream without significant transformation in the riparian zone. The catchment is divided into three parcels which have existed since 2000. The standard crop rotation is dominated by winter wheat (Triticum aestivum L .), rapeseed (Brassica napus), summer oats (Avena sativa) and alfalfa (Medicago sativa).

The soils are developed on Paleozoic conglomerate with arenaceous and rudaceous texture and are classified as Haplic Luvisols and Cambisols. The soil texture is considered sandy loam (9\% clay, $58 \%$ silt, and $33 \%$ sand on average). Several geophysical surveys using electrical resistivity tomography (ERT) have been conducted to capture the degree of homogeneity/heterogeneity present in the compacted layer and to determine the depth of the bedrock. Based on geophysical monitoring and a geological borehole survey conducted at a close-by location, the bedrock ranges in depth from 6-20 m. The soil is tilled to approximately $12 \mathrm{~cm}$, below the tilled topsoil there is a compacted plough pan with very low hydraulic permeability.

The catchment is often very dry during the summer and the baseflow recorded at the closing profile declines to $0-0.2 \mathrm{l} \mathrm{s}^{-1}$, in winter and early spring the baseflow is around $4 \mathrm{l} \mathrm{s}^{-1}$. The average annual runoff coefficient is $1 \%$. The runoff formation during the rainfall events exhibits threshold behavior. Based on the measured rainfall-runoff data, we have identified rather scattered rainfall-runoff relationship with a strong dependence of the runoff on the actual topsoil saturation. Different runoff pathways and runoff mechanisms have been observed. Once the soil moisture conditions are below a certain threshold value, the magnitude of the stormflow is not correlated to rainfall totals. Therefore, the shallow topsoil and its water holding capacity play a significant role in runoff formation. As the topsoil becomes saturated on a large part of the catchment, water is quickly routed via surface (especially through the compacted wheel tracks in the slope wise direction) and shallow subsurface runoff toward the drainage channel. Even though the channel is straight and short, the hydrographs and especially sedigraphs are transformed strongly during the summer events due to dense vegetation on the stream banks .

\section{Dataset}

The catchment is equipped with instrumentation for basic meteorological, hydrological, and hydropedological variable monitoring. Most of the variables are recorded at 5-minute intervals, soil water content hourly. Discharge is monitored at two locations in the stream. Firstly, in the culvert below the upper field a pressure probe is installed for water depth monitoring, the discharge is calculated based on the calibrated rating curve. Secondly, at the closing profile there is an H-flume with capacity of $400 \mathrm{l} \mathrm{s}^{-1}$ serially connected to a V-notch 
weir with the capacity of $5 \mathrm{l} \mathrm{s}^{-1}$. The water depth is measured by pressure transducers (LMP307, BD Sensors) and a sonic distance sensor (SR50A, Campbell Sci.). Stream water temperature, electrical conductivity (CS547A, Campbell Sci.), and turbidity (VisoTurb® 700 IQ, WTW) are also monitored. Three rain gauges (tipping buckets with $0.1 \mathrm{~mm}$ and $0.2 \mathrm{~mm}$ resolutions, MR3 Meteoservis \& Pronamic, respectively) are distributed across the catchment. The meteorological station records temperature, humidity (EMS33H, EMS), wind speed and direction (03002, R. M. Young), and net radiation (NR Lite 2, Kipp \& Zonen). Groundwater level is monitored via piezometers (LMP307, BD Sensors) at the closing profile and in the upper part of the catchment. The soil water regime is monitored at two points by water content reflectometers (CS650, Campbell Sci.) at depths from 10 to $60 \mathrm{~cm}$. Two cosmic-rays neutron sensors (Cosmic-Ray Neutron Detector System, StyX Neutronica) are installed in the catchment for larger scale topsoil water content estimation (Figure 1).

The precipitation data contains the records from two rain gauges (Rain_1 and Rain_2) (Figure 1). Rainfall observations near the catchment's outlet (Rain_1) have been recorded since 2013 while the rain gauge in the upper field (Rain_2) has data from the end of 2019. All the precipitation records in the dataset have been post-processed for quality control assurance (to exclude extreme values caused by measurement errors). The temperature has been recorded simultaneously at the same locations as precipitation: near the outlet (Rain _1) since 2013 and the Rain_2 station from the end of 2019. The dataset contains temperature data including daily minimums, averages, and maximums at both stations. Additionally, daily reference evapotranspiration was recorded at the Rain_1 meteorological station from 2013 and saved in the same file as temperature data.

For the hydrological data, the stream discharge in the dataset includes the measured discharge at the catchment outlet since the end of 2013. Quality control of the runoff data (removal of extreme values caused by measurement errors) was implemented and the modified runoff was saved at a 10-minute time resolution. Based on the runoff observation, one or two peak flows usually happen in the summer after intensive summer storms. In addition, the measurement errors of runoff have often occurred during the winter (Figure 2). Moreover, the dataset contains temporal soil moisture records from two points: one is located near the outlet (SWC_1: 3 depths from 10 to $40 \mathrm{~cm}$ ) since the end of 2013, the other one is close to the powerline (SWC_2: 6 depths from 10 to $60 \mathrm{~cm}$ ) since the end of 2019 (Figure 1). In general, the soil moisture dynamics (especially the topsoil) are behaviorally similar to the runoff variation (Figure 2). The soil moisture in the upper layer has a higher degree of fluctuation than the lower layers (Figure 3). To summarize the data and provide a more comprehensive perspective of the observations for each year, we have included metadata and an annual report in the dataset. However, since more devices have been deployed at the catchment recently, the dataset will be updated regularly with the observed data from the newly deployed devices.

\section{Application}

\subsection{Application of the data}

The hydrometeorological dataset in Nučice has been primarily used for the investigation of hydrological responses under the impacts of agricultural activities. The observed rainfall runoff events were evaluated to determine the storm runoff generation mechanisms in the catchment . estimated the effects of tillage and rainfall intensity on topsoil unsaturated hydraulic conductivity by utilizing precipitation and temporal soil moisture observations. Numerical models (Hydrus/SWAT/MIKE-SHE) have been applied from plot to catchment scale to design and validate optimal agricultural management practices which can increase water storage capacity within the catchment .

\subsection{Data availability}

The Nučice dataset is available at http://storm.fsv.cvut.cz/o-nas/vybaveni/povodi/nucice. For more information of the dataset, please contact the corresponding author Tailin Li: tailin.li@fsv.cvut.cz. 


\section{Acknowledgement}

This work has been supported by Project SHui which is co-funded by the European Union Project: 773903 and the Chinese MOST.

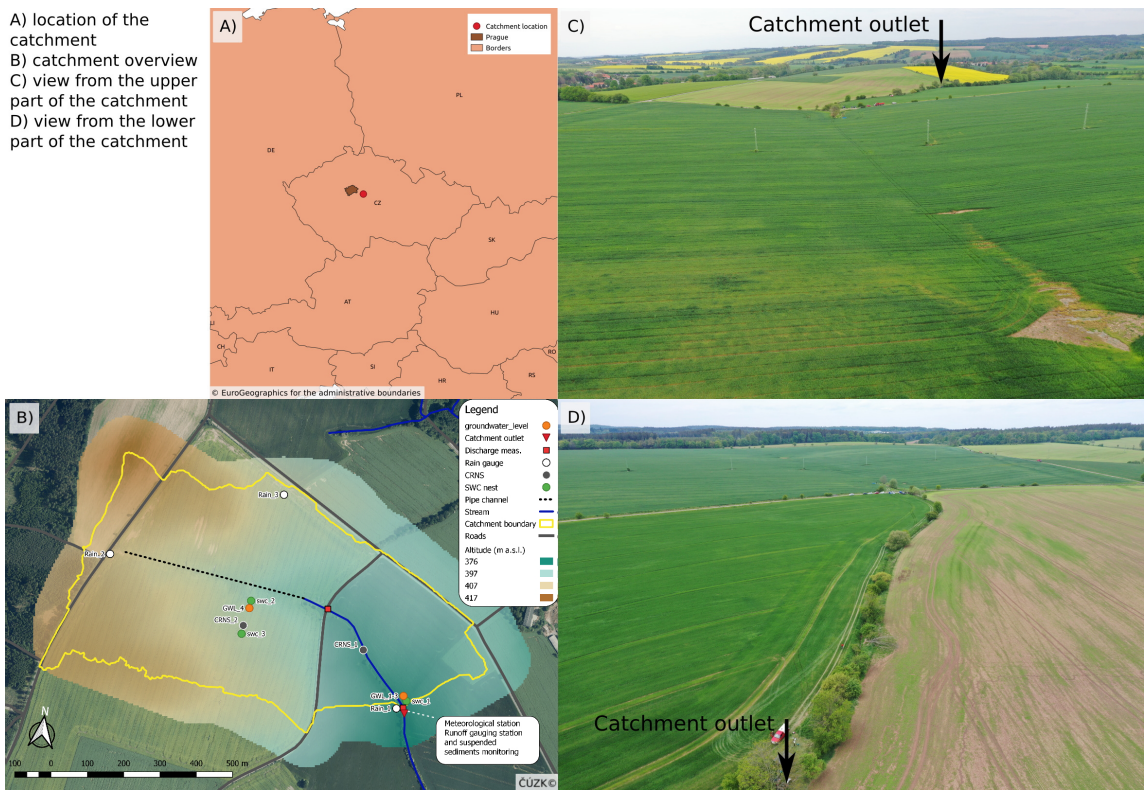


daily precipitation $(\mathrm{mm})$
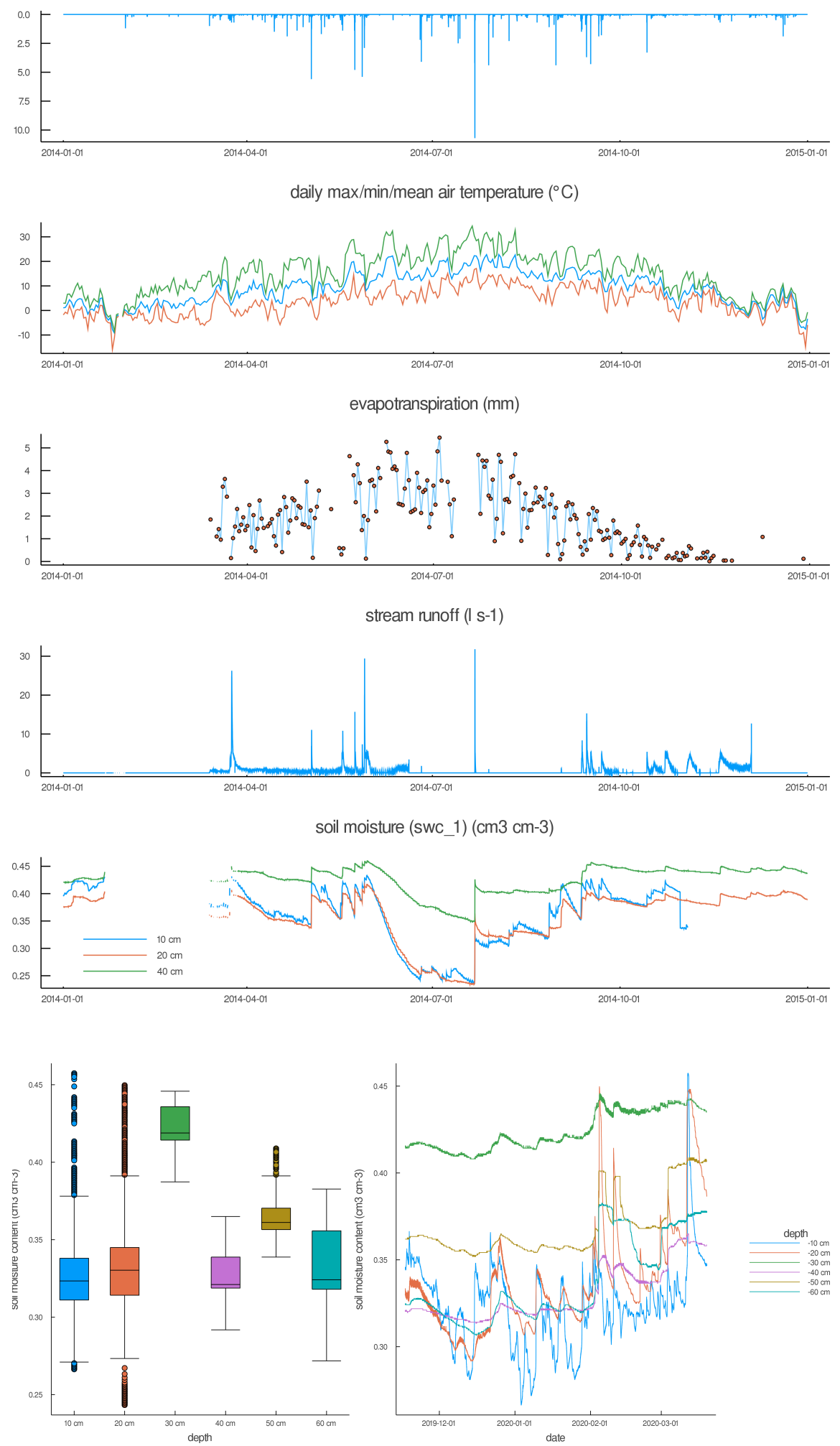